\title{
Impact of visceral adiposity on severity of acute pancreatitis: a propensity score- matched analysis
}

\author{
Jiarong Xie ${ }^{1,2+}$, Lu Xu ${ }^{1,2+}$, Yuning Pan ${ }^{3}$, Peifei Li, ${ }^{2,4}$, Yi Liü ${ }^{2,4}$, Yue Pan ${ }^{2,4}$ and Lei $X u^{2,4^{*}}$
}

\begin{abstract}
Background: The relationship between visceral adiposity and acute pancreatitis (AP) has not been completely elucidated. This study evaluated the significance of visceral adipose tissue (VAT) and the ratio of VAT to skeletal muscle tissue (VAT/SMT) in the prognosis of AP patients.

Methods: Based on a 1:2 propensity score matching, 306 hospitalized patients were enrolled in the study analysis from 2010 to 2017. VAT, subcutaneous adipose tissue (SAT), and SMT were measured using unenhanced computed tomography $(\mathrm{CT})$. Cox proportional hazards models were applied for the analysis.

Results: VAT and the VAT/SMT ratio were significantly higher in the severe AP (SAP) and moderately severe AP (MSAP) groups compared to the mild AP (MAP) group (both $p<0.001)$. Intensive care transfer, AP severity, systemic complications, and prognostic scores (Acute Physiology and Chronic Health Evaluation II [APACHE-II] score $\geq 8$, Ranson's score $\geq 3$, Bedside Index of Severity in Acute Pancreatitis [BISAP] score $\geq 3$, and the systemic inflammatory response syndrome [SIRS] score $\geq 2$ ) significantly correlated with VAT and the VAT/SMT ratio in AP patients. The multivariate adjusted hazard ratios (HRs) for VAT and the VAT/SMT ratio in the relationship of body parameters and AP mortality were 1.042 (95\% confidence interval (Cl), 1.019-1.066) and 7.820 (95\% Cl, 1.978-30.917), respectively. Compared with other prognostic scores, VAT had the highest area under the curve of receiver operating characteristics (ROC) $(0.943,95 \% \mathrm{Cl}, 0.909-0.976)$.
\end{abstract}

Conclusion: High VAT and VAT/SMT ratio are independent negative prognostic indicators of AP.

Trial registration: Clinical study registration number: NCT03482921. Date of registration: 03/23/2018.

Keywords: Visceral adiposity, Skeletal muscle tissue, Acute pancreatitis, Predictor, Computed tomography

\section{Background}

Acute pancreatitis (AP) is cause by inflammation of the pancreas. In the majority of cases, AP is mild and selflimited. However, about $20 \%$ of AP patients experience severe complications with a high risk of mortality $[1,2]$. It is vital to classify severe AP cases early in the evolution of the disease, because severe cases require more aggressive treatment to achieve the best possible results and reduce complications [3]. Historically, several scoring systems

\footnotetext{
* Correspondence: xulei22@163.com

† Jiarong Xie and Lu Xu contributed equally to this work.

2Department of Gastroenterology, Ningbo First Hospital, No.59 Liuting Street, Haishu District, Ningbo, Zhejiang Province, China

${ }^{4}$ Laboratory of Digestive Diseases, Ningbo First Hospital, No.59 Liuting Street, Haishu District, Ningbo, Zhejiang Province, China

Full list of author information is available at the end of the article
}

have been developed and widely utilized to determine AP severity: Acute Physiology and Chronic Health Evaluation II (APACHE-II) score, Bedside Index of Severity in Acute Pancreatitis (BISAP) score, and Ranson's score [4-6]. Each of these scoring systems has its advantages and limitations. Other systems have also been developed and many others are currently being created. However, it has remained difficult to identify the most effective method to predict AP severity at an early stage.

It is well-established that obesity (defined as body mass index $(\mathrm{BMI})>30 \mathrm{~kg} / \mathrm{m}^{2}$ by the World Health Organization) is a risk factor for AP severity and increases the incidence of systemic complications and mortality [7-9]. BMI measurements and waist circumference are often viewed as indicators of being overweight. One disadvantage of these

(c) The Author(s). 2019 Open Access This article is distributed under the terms of the Creative Commons Attribution 4.0 International License (http://creativecommons.org/licenses/by/4.0/), which permits unrestricted use, distribution, and reproduction in any medium, provided you give appropriate credit to the original author(s) and the source, provide a link to the Creative Commons license, and indicate if changes were made. The Creative Commons Public Domain Dedication waiver (http://creativecommons.org/publicdomain/zero/1.0/) applies to the data made available in this article, unless otherwise stated. 
parameters is that they do not distinguish between truncal obesity and visceral obesity. This is significant because fat distribution plays an important role in AP severity. In recent years, many parameters related to sarcopenic obesity, including visceral adipose tissue (VAT), subcutaneous adipose tissue (SAT), skeletal muscle tissue (SMT), and the VAT/ SMT ratio, have been considered important risk factors of AP [10-13]. Some recent reports indicated that increased VAT is more closely associated with AP severity compared to BMI $[10,14-16]$. However, it is unclear which parameter is the best predictor of AP severity [17]. There are very few studies in the literature that address the association between body composition parameters and clinical outcomes in AP. Thus, this study explored the association between these parameters and AP severity to elucidate which is the most suitable predictor of AP.

\section{Methods}

\section{Study population}

We analyzed 1662 consecutive hospitalized patients with AP between August 1st, 2010 and August 31st, 2017 at Ningbo First Hospital, China. This study was approved by the $\mathrm{Hu}-$ man Ethics Committee. The clinical study registration number is NCT03482921. Severe AP (SAP) and moderately severe AP (MSAP) were defined in 111 patients according to the Revised Atlanta Classification of AP [18] (Fig. 1). Exclusion criteria for the study included age $<18$ years, missing data in the electronic medical record, and history of AP. Nine unqualified patients were excluded. SPSS R plug-in (SPSS R Essentials) was applied for matching [19]. We used the SPSS "PS Matching" feature to perform propensity score-matched analysis. Matching factors include age, sex, and BMI. SAP, and MSAP patients were matched 1:2 in a multivariable logistic analysis using stepwise regression based on a greedy matching algorithm with a caliper of 0.2 times the standard deviation (SD) of the logit. After applying 1:2 propensity score matching, 102 eligible patients were matched to 204 patients with mild AP (MAP). In total, 306 hospitalized patients were enrolled in this study.

\section{Severity assessment}

AP severity was defined using the Revised Atlanta Classification criteria. The clinical classification defined 3 grades of severity: MAP, MSAP, and SAP.

\section{Definition of systemic complications}

Systemic complication was defined as a score $\geq 2$ in one of three assessed organ systems (respiratory, cardiovascular, or renal) according to the modified Marshall scoring system [20].

\section{Definition of local complications}

Local complications of AP were divided into: acute peripancreatic fluid collection (APFC), acute necrotic collection (ANC), pancreatic pseudocyst, and walled-off necrosis (WON). Diagnosis of local complication on unenhanced computed tomography (CT) was evaluated by two experienced radiologists who were blinded to detailed information about the cases. When necessary, follow-up contrastenhanced CT (CECT) and magnetic resonance imaging (MRI) are performed based on the clinical status of patients, including persistence or recurrence of abdominal pain, increasing organ dysfunction, and development of clinical signs of sepsis. Once patients are diagnosed with APFC, ANC, WON, or pseudocyst in the follow-up imaging examinations, they are considered to present with local complications.

\section{Laboratory tests}

Creatinine, calcium, and albumin levels obtained within the first $24 \mathrm{~h}$ were collected for each patient. Additional variables included intensive care unit (ICU) requirement, length of hospital stay, and in-hospital mortality.

\section{Combined scoring systems}

The APACHE-II, BISAP, and SIRS scores were calculated within the first $24 \mathrm{~h}$ of admission, and Ranson's score was recorded within $48 \mathrm{~h}$ of admission.

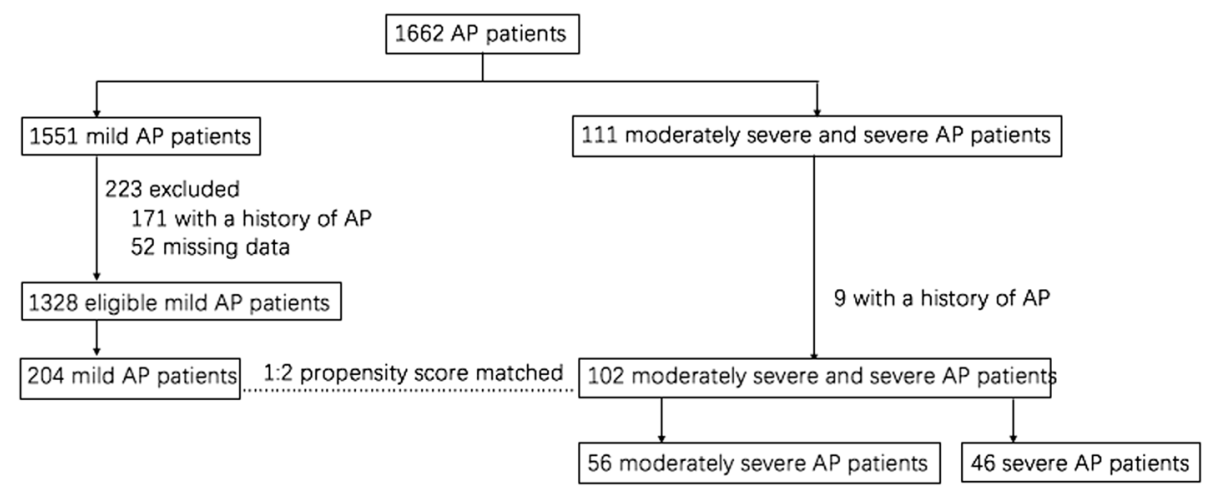

Fig. 1 Study flowchart 


\section{$\mathrm{CT}$ and image analysis}

A dual 16-slice CT scanner (SIMENS SOMATOM Sensation; Siemens, Germany) was used for entire / upper abdominal CT at $250 \mathrm{~mA}$; tube voltage, $120 \mathrm{kV}$; data collection thickness $5 \mathrm{~mm}$; reconstruction thickness 1 $\mathrm{mm}$; and reconstruction interval $1 \mathrm{~mm}$. CT scans were performed within $24 \mathrm{~h}$ after patient admission. Entire abdomen CT was performed to 165 patients. Upper abdomen CT was performed to 141 patients. Two consecutive, axial images on unenhanced CT at the L3/4 intervertebral space were retrospectively reviewed by two radiologists who were blinded to patient information. We calculated fat and muscle cross-sectional areas, which have been validated as the best proxies of SAT and VAT independent of age [21]. Skeletal muscle areas, including the psoas, paraspinal, and the abdominal wall muscles excluding the intra-abdominal visceral muscles, were also measured (Fig. 2). We used the Photoshop "magic wand" to outline and measure regions of similar signal intensity based on pixel counts. We manually outlined the margin of fat deposition manually in fat-tissue regions with poor contrast, which may be a more accurate way to measure compartment volumes. The Hounsfield units (HU) range for adipose tissue was - 190 to $30 \mathrm{HU}$ [22]. The mean value of the two images was calculated. The abdominal muscular wall distinguishing between VAT and SAT was traced automatically and adjusted manually $[23,24]$. The VAT/SMT ratio was calculated by dividing VAT by SMT. All CT scans were analyzed using a commercially available software program (Photoshop CS6, Adobe Systems, CA) [25].

\section{Statistical analysis}

Continuous variables are expressed as mean \pm standard deviation (SD) and median (interquartile range). Categorical outcomes are presented as frequencies and proportions. Comparisons of different variables were performed using one-way analysis of variance (ANOVA) and Likelihood Ratio. Cox regression analysis adjusted for confounders were used to identify the relationships. Discrimination of the predicting factors, including VAT and VAT/SMT ratio, were accomplished via receiver operating characteristic (ROC) curves. A two-tailed $p$ value $<$ 0.05 was considered statistically significant. All statistical analyses were performed using SPSS software (version 23.0; SPSS, Chicago, IL).

\section{Results}

\section{Baseline characteristics}

In this study, every MSAP and SAP patient was propensity score matched with another MAP patient at a ratio of 1:2. Finally, 306 hospitalized patients were enrolled for further analysis. Among the 306 patients, causative factors of AP included gallstone-related (142; 46.4\%), idiopathic (91; 29.7\%), hypertriglyceridemia (48; 15.7\%), alcohol abuse (22; 7.2\%), and others $(3 ; 1.0 \%)$. The mean age of the patients was $50.6 \pm 18.7$ years. The mean estimated BMI was $24.4 \pm 4.5 \mathrm{~kg} / \mathrm{m}^{2}$. The mean SAT value was $131.1 \pm 23.1$ $\mathrm{cm}^{2}$. The mean VAT value was $136.1 \pm 27.3 \mathrm{~cm}^{2}$. The mean SMT value was $138.2 \pm 25.8 \mathrm{~cm}^{2}$.

\section{Comparisons of characteristics according to AP severity}

Age, sex, and BMI distribution were not statistically different among groups after propensity matching. There was a significant association between AP severity and individual fat parameters, except for SAT (Table 1). VAT and the VAT/SMT ratio were significantly higher in the MSAP and SAP groups compared to the MAP group (both $p<0.001$ ). The mean SMT values decreased as AP severity increased $(\mathrm{p}<0.001)$.

\section{Relationship between body parameters and severity outcomes}

Based on the VAT value at the L3/4 intervertebral space, patients were separated into five groups. ICU transfer, AP severity, and systemic complications (APACHE-II scores $\geq 8$, BISAP score $\geq 3$, SIRS score $\geq 2$ ) were significantly related to VAT values in the AP patients (Table 2).

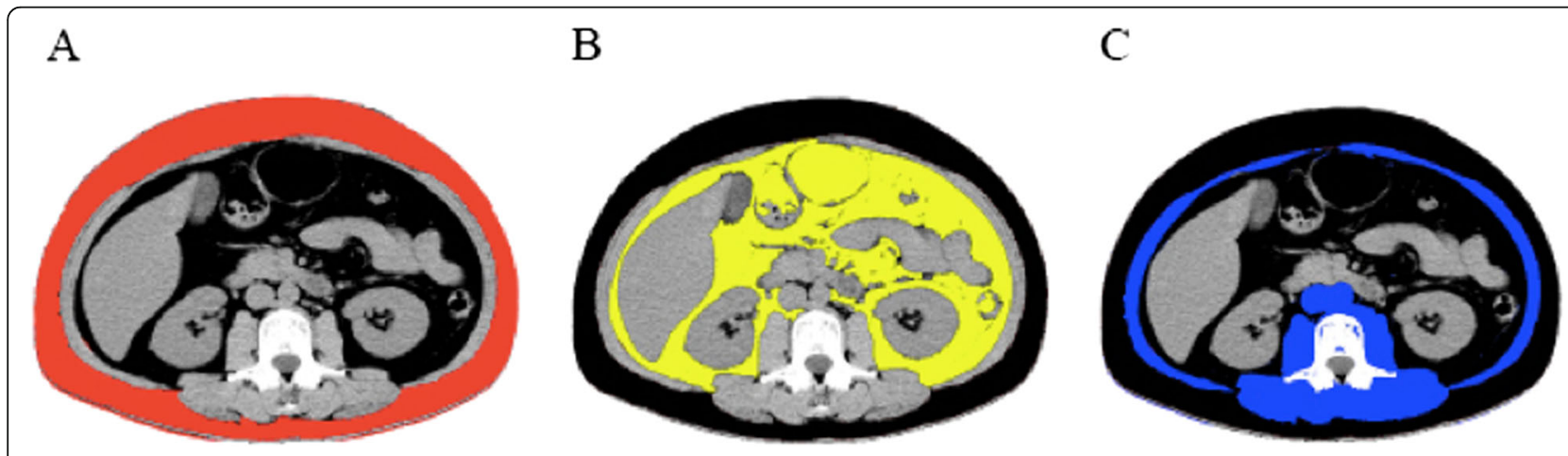

Fig. 2 a Subcutaneous adipose tissue (SAT) (red) was calculated within the region of interest (ROI) by selection of pixels at the $L 3 / 4$ intervertebral space b Visceral adipose tissue (VAT) (yellow) c Skeletal muscle tissue (SMT) (blue) 
Table 1 Clinical characteristics of patients stratified by AP severity

\begin{tabular}{|c|c|c|c|c|c|}
\hline & \multirow{2}{*}{$\begin{array}{l}\text { Total } \\
(n=306)\end{array}$} & \multicolumn{3}{|c|}{ Severity of AP } & \multirow[t]{2}{*}{$p$ value } \\
\hline & & $\begin{array}{l}\text { Mild } \\
(n=204)\end{array}$ & $\begin{array}{l}\text { Moderately severe } \\
(n=56)\end{array}$ & $\begin{array}{l}\text { Severe } \\
(n=46)\end{array}$ & \\
\hline Age (years) & $50.6 \pm 18.7$ & $50.4 \pm 18.7$ & $49.4 \pm 18.9$ & $52.8 \pm 19.3$ & 0.632 \\
\hline Sex, male (\%) & $157(51.3 \%)$ & $107(52.5 \%)$ & $25(44.6 \%)$ & $25(54.3 \%)$ & 0.552 \\
\hline $\mathrm{BMI}\left(\mathrm{kg} / \mathrm{m}^{2}\right)$ & $24.4 \pm 4.5$ & $24.2 \pm 5.0$ & $24.7 \pm 2.7$ & $25.3 \pm 3.1$ & 0.505 \\
\hline \multicolumn{6}{|c|}{ Fat volume parameters $\left(\mathrm{cm}^{2}\right)$} \\
\hline SAT & $131.1 \pm 23.1$ & $128.1 \pm 22.1$ & $138.8 \pm 22.4$ & $134.6 \pm 25.8$ & 0.04 \\
\hline VAT & $136.1 \pm 27.3$ & $121.6 \pm 17.3$ & $154.1 \pm 15.1$ & $178.7 \pm 15.2$ & $<0.001$ \\
\hline SMT & $138.2 \pm 25.8$ & $143.5 \pm 25.8$ & $130.6 \pm 20.2$ & $123.7 \pm 24.5$ & $<0.001$ \\
\hline VAT/SMT ratio & $1.03 \pm 0.32$ & $0.87 \pm 0.21$ & $1.21 \pm 0.21$ & $1.49 \pm 0.26$ & $<0.001$ \\
\hline
\end{tabular}

$B M I$, Body mass index; SAT, Subcutaneous adipose tissue; VAT, Visceral adipose tissue; SMT, Skeletal muscle tissue

Student Newman-Keuls post hoc comparisons of fat volume parameters were assessed between three groups $(p<0.05$, respectively)

Patients were also separated into five groups according to the VAT/SMT ratio. ICU transfer, AP severity, systemic complications, and prognostic scores (APACHE-II scores $\geq 8$, Ranson's score $\geq 3$, BISAP score $\geq 3$, SIRS score $\geq 2$ ) had significant relationship with the VAT/ SMT ratio (Table 3).

\section{Confounding variables}

Further analyses were conducted for creatinine, calcium, and albumin levels using an adjusted model (Table 4). The multivariate adjusted hazard ratios (HRs) for VAT and the VAT/SMT ratio in the relationship between body parameters and AP mortality were 1.042 (95\% confidence interval (CI), 1.019-1.066) and 7.820 (95\% CI, 1.978-30.917), respectively. The VAT/SMT ratio was positively related to the incidence of AP mortality $(p<$ $0.001)$.

\section{Comparisons of independent predictors}

The AUCs were measured to evaluate individual fat parameters of VAT and the VAT/SMT ratio for predicting the incidence of SAP and MSAP, ICU stay, and the incidence of WON (Fig. 3).

VAT had the highest area under the curve of ROC (0.943, 95\% CI, 0.909-0.976) for predicting the incidence of SAP and MSAP, among independent predictors. The AUC of the VAT/SMT ratio was also significantly higher compared to the predictive scoring systems $(0.896,95 \%$ CI, 0.856-0.936). The optimal cut-off value of VAT for the prognosis of AP was

Table 2 Relationships between VAT and severity outcomes

\begin{tabular}{|c|c|c|c|c|c|c|}
\hline $\operatorname{VAT}\left(\mathrm{cm}^{2}\right)$ & $<90$ & $90-120$ & $120-150$ & $150-180$ & $>180$ & $p$ value \\
\hline Number of patients & 7 & 97 & 103 & 69 & 30 & \\
\hline ICU transfer & $0(0 \%)$ & $2(2.1 \%)$ & $5(4.9 \%)$ & 27 (39.1\%) & $24(80.0 \%)$ & $<0.001$ \\
\hline SAP & $0(0 \%)$ & $0(0 \%)$ & $4(3.9 \%)$ & $13(18.8 \%)$ & $29(96.7 \%)$ & $<0.001$ \\
\hline Mortality & $0(0 \%)$ & $0(0 \%)$ & $4(3.9 \%)$ & $8(11.6 \%)$ & $15(50 \%)$ & $<0.001$ \\
\hline Systemic complications & $0(0 \%)$ & $3(3.1 \%)$ & $10(9.7 \%)$ & $40(58.0 \%)$ & $29(96.7 \%)$ & $<0.001$ \\
\hline \multicolumn{7}{|l|}{ Local complications } \\
\hline APFC & $2(28.6 \%)$ & 38 (39.2\%) & $28(27.2 \%)$ & $26(37.7 \%)$ & $16(53.3 \%)$ & 0.107 \\
\hline ANC & $0(0 \%)$ & $0(0 \%)$ & $0(0 \%)$ & $8(11.6 \%)$ & $3(10.0 \%)$ & $<0.001$ \\
\hline WON & $0(0 \%)$ & $1(1.0 \%)$ & $5(4.9 \%)$ & $6(8.7 \%)$ & $4(13.3 \%)$ & 0.038 \\
\hline Pancreatic pseudocyst & $0(0 \%)$ & $2(2.1 \%)$ & $6(5.8 \%)$ & $8(11.6 \%)$ & $3(10.0 \%)$ & 0.088 \\
\hline \multicolumn{7}{|l|}{ Prognostic scores } \\
\hline APACHE-\| score $\geq 8$ & $0(0 \%)$ & $7(7.2 \%)$ & $8(7.8 \%)$ & $17(24.6 \%)$ & $21(70.0 \%)$ & $<0.001$ \\
\hline Ranson's score $\geq 3$ & $0(0 \%)$ & $7(7.2 \%)$ & $6(5.8 \%)$ & $9(13.0 \%)$ & $14(46.7 \%)$ & $<0.001$ \\
\hline BISAP score $\geq 3$ & $0(0 \%)$ & $2(2.1 \%)$ & $3(2.9 \%)$ & $4(5.8 \%)$ & $5(16.7 \%)$ & 0.048 \\
\hline SIRS score $\geq 2$ & 1 (14.3\%) & $12(12.4 \%)$ & $22(21.4 \%)$ & 40 (58.0\%) & $21(70.0 \%)$ & $<0.001$ \\
\hline
\end{tabular}

VAT, Visceral adipose tissue; ICU, Intensive care unit; SAP, Severe acute pancreatitis; APFC, Acute peripancreatic fluid collection; ANC, Acute necrotic collection; WON, Walled-off necrosis; APACHE-II, Acute Physiology and Chronic Health Evaluation II; BISAP, Bedside Index of Severity in Acute Pancreatitis; SIRS, systemic inflammatory response syndrome 
Table 3 Relationship between the VAT/SMT ratio and severity outcomes

\begin{tabular}{|c|c|c|c|c|c|c|}
\hline VAT/SMT ratio & $<0.6$ & $0.6-0.9$ & $0.9-1.2$ & $1.2-1.5$ & $>1.5$ & $p$ value \\
\hline Number of patients & 7 & 147 & 60 & 56 & 36 & \\
\hline ICU transfer & $0(0 \%)$ & $5(3.4 \%)$ & $6(10.0 \%)$ & $22(39.3 \%)$ & $25(69.4 \%)$ & $<0.001$ \\
\hline SAP & $0(0 \%)$ & $2(1.4 \%)$ & $5(8.3 \%)$ & $11(19.6 \%)$ & $28(77.8 \%)$ & $<0.001$ \\
\hline Mortality & $0(0 \%)$ & $2(1.4 \%)$ & $4(6.7 \%)$ & $8(14.3 \%)$ & $13(36.1 \%)$ & $<0.001$ \\
\hline Systemic complications & $0(0 \%)$ & $7(4.8 \%)$ & $19(31.7 \%)$ & $28(50 \%)$ & $28(77.8 \%)$ & $<0.001$ \\
\hline \multicolumn{7}{|l|}{ Local complications } \\
\hline APFC & $2(28.6 \%)$ & 49 (33.3\%) & $22(36.7 \%)$ & $22(39.3 \%)$ & $15(41.7 \%)$ & 0.859 \\
\hline ANC & $0(0 \%)$ & $0(0 \%)$ & $4(6.7 \%)$ & $5(8.9 \%)$ & $2(5.6 \%)$ & 0.002 \\
\hline WON & $0(0 \%)$ & $2(1.4 \%)$ & $5(8.3 \%)$ & $4(7.1 \%)$ & $5(13.9 \%)$ & 0.017 \\
\hline Pancreatic pseudocyst & $0(0 \%)$ & $2(1.4 \%)$ & $3(5.0 \%)$ & $9(16.1 \%)$ & $5(13.9 \%)$ & 0.01 \\
\hline \multicolumn{7}{|l|}{ Prognostic scores } \\
\hline APACHE-II score $\geq 8$ & $0(0 \%)$ & $13(8.8 \%)$ & $8(13.3 \%)$ & $13(23.2 \%)$ & $19(52.8 \%)$ & $<0.001$ \\
\hline Ranson's score $\geq 3$ & $0(0 \%)$ & $9(6.1 \%)$ & $6(10.0 \%)$ & $8(14.3 \%)$ & $13(36.1 \%)$ & $<0.001$ \\
\hline BISAP score $\geq 3$ & $0(0 \%)$ & $2(1.4 \%)$ & $1(1.7 \%)$ & $5(8.9 \%)$ & $6(16.7 \%)$ & 0.002 \\
\hline SIRS score $\geq 2$ & $1(14.3 \%)$ & $22(15.0 \%)$ & 17 (28.3\%) & $32(57.1 \%)$ & $24(66.7 \%)$ & $<0.001$ \\
\hline
\end{tabular}

VAT, Visceral adipose tissue; SMT, Skeletal muscle tissue; ICU, Intensive care unit; SAP, Severe acute pancreatitis; APFC, Acute peripancreatic fluid collection; ANC, Acute necrotic collection; WON, Walled-off necrosis; APACHE-II, Acute Physiology and Chronic Health Evaluation II; BISAP, Bedside Index of Severity in Acute Pancreatitis; SIRS, Systemic inflammatory response syndrome

145.0. The sensitivity and specificity of this cut-off value were 90.2 and $93.1 \%$, respectively. The optimal cut-off point of the VAT/SMT ratio for the prognosis of AP was 0.706 . The sensitivity and specificity of this cut-off value were 80.4 and $90.2 \%$, respectively. The cut-off values for VAT and the VAT/SMT ratio can be used to predict the incidence of SAP and MSAP.

We also demonstrated that VAT and the VAT/SMT ratio had high sensitivity and specificity for predicting the incidence of ICU stay and WON compared to other predictive scoring systems. The AUC of VAT for predicting the incidence of ICU stay was 0.900 (95\% CI, 0.8510.949). The second highest AUC of ROC was the VAT/ SMT ratio $(0.865,95 \% \mathrm{CI}, 0.810-0.921)$. The AUC of the VAT/SMT ratio was the highest predictor of the incidence WON (0.745, 95\% CI, 0.628-0.863).

\section{Discussion}

This propensity score-matched, case-control study assessed the significance of VAT and the VAT/SMT ratio as AP prognostic factors. VAT and the VAT/SMT ratio increased as AP severity increased, including the incidence of SAP and MSAP, the incidence of ICU transfer, and the incidence of WON. This study also calculated the optimal cut-off values, which can be used to predict AP severity.

AP involves sudden inflammation in the pancreas. Early prediction of SAP will allow more aggressive management at early stages of the disease. There are many SAP predictive scoring systems. However, none can predict the severity at early stages of AP. If initial CT scans in AP patients are routinely performed at an early stage, the values of VAT and the VAT/SMT ratio could be quickly calculated and used as predictors.

Table 4 Multivariate adjusted HRs and 95\% Cls for the association between body parameters and AP mortality

\begin{tabular}{|c|c|c|c|c|}
\hline \multirow[t]{3}{*}{ Variables } & \multicolumn{4}{|c|}{ All of the participants $(n=264)$} \\
\hline & \multicolumn{2}{|l|}{ Model1 } & \multicolumn{2}{|l|}{ Model2 } \\
\hline & $\mathrm{HR}(95 \% \mathrm{Cl})$ & $p$ value & $\mathrm{HR}(95 \% \mathrm{Cl})$ & $p$ value \\
\hline VAT, $\mathrm{cm}^{2}$ & $1.042(1.019-1.066)$ & $<0.001$ & & \\
\hline VAT/SMT ratio & & & $7.820(1.978-30.917)$ & 0.003 \\
\hline Creatinine & $1.003(1.001-1.006)$ & 0.014 & $1.004(1.001-1.007)$ & 0.005 \\
\hline Calcium & $0.498(0.103-2.413)$ & 0.387 & $0.232(0.045-1.184)$ & 0.079 \\
\hline Albumin & $0.986(0.921-1.056)$ & 0.682 & $0.992(0.925-1.063)$ & 0.812 \\
\hline
\end{tabular}

VAT, visceral adipose tissue; SMT, skeletal muscle tissue

Model 1 and model 2 were based on the VAT and the VAT/SMT ratio, respectively. Cox proportional hazard models were used to estimate the HRs, 95\% Cis, and $p$ values 



Fig. 3 ROC analysis. a Diagnostic assessment of the independent predictors for acute pancreatitis (AP) severity; b Diagnostic assessment of the independent predictors for the incidence of intensive care unit (ICU) stay; c Diagnostic assessment of the independent predictors for the incidence of walled-off necrosis (WON)

Obesity is a well-established risk factor of severity and mortality in AP patients $[9,26]$. In previous studies, obesity was determined as $\mathrm{BMI}>30 \mathrm{~kg} / \mathrm{m}^{2}$. However, Asians tend to have a significantly lower BMI, at approximately $2-3 \mathrm{~kg} / \mathrm{m}^{2}$ lower compared to age and sex matched whites with the same amount of body fat [27]. Currently, there is no universal tool to predict prognosis and mortality in AP patients [28-33]. In addition, the scoring tools do not distinguish between truncal obesity and visceral obesity. Some studies showed that VAT significantly correlates with poor outcomes in AP patients [10, 14-16]. Therefore, we investigated the relationship between body parameters, prognosis, and mortality in AP patients. This study showed that VAT and the VAT/ SMT ratio were significantly higher in the MSAP and SAP groups compared to the MAP group. Besides, VAT, and VAT/SMT ratio had the highest AUC in predicting the incidence of SAP and MSAP, the incidence of ICU transfer, and the incidence of WON. VAT and the VAT/ SMT ration could therefore be used to distinguish AP severity by applying VAT and the VAT/SMT ratio scoring in clinical practice.

Previous studies reported gender-based variations in fat distribution, especially in obese patients [34, 35]. Risk of disease, as well as visceral fat, increases dramatically with age $[36,37]$. In our study, every high-risk case was propensity score matched at a 1:2 ratio with another patient with MAP. Matching was based on patient demographics (age, sex, and BMI), which decreased bias and effectively controlled for confounding variables. Some clinical characteristics, such as creatinine, calcium, and albumin levels, are typically considered biomarkers associated with disease prognosis and mortality. These characteristics have often been considered in the AP scoring systems [4, 38, 39]. We used Cox proportional hazard models adjusted for creatinine, calcium, and albumin levels, which may reduce the bias. The mean value of two images were reviewed by two dedicated radiologists blinded to clinical and demographic data to increase the accuracy of our results.

There are four studies that have presented similar results to the finding described here. A study of 62 cases [15] reported a close relationship between AP severity, systemic complications, and individual fat parameters. Another study of 124 patients [14] demonstrated that VAT volume is significantly associated with SAP but not BMI or waist circumference. Yoon et al. [10] found that high visceral fat with low skeletal muscle volume plays an important role in AP severity. Natu et al. [16] found that VAT is closely associated with organ failure and necrosis in AP. However, there are some limitations. Some of these studies did not focus on body parameter classifications. Furthermore, they did not provide clinical characteristics of the patients, such as creatinine, calcium, and albumin, which could act as confounding variables. Moreover, since the first two studies were published before the revised version appeared, they used the previous version of the Atlanta classification, which is not as precise as other measures. Our study investigated the relationship between different body parameters and AP severity. To our knowledge, this study is the largest describing these parameters.

There are several limitations in our study. First, at present, it is difficult to perform a CT scan on a patient within $24 \mathrm{~h}$ after admission in some countries and regions. Second, due to its retrospective design, the statistical power of analysis is relatively weak. Third, individuals from the Chinese population were included in our study. We did not recruit AP patients in western countries, which may increase potential bias. 
This is the largest study exploring the relationship between different body parameters and severity of AP after taking several covariates into account. Furthermore, we calculated the optimal cut-off value of VAT and the VAT/SMT ratio. Therefore, VAT and the VAT/SMT ratio should be considered as independent predictors in AP patients. To extend our results to clinical-decision making, further randomized, multi-center, prospective studies that include different countries and regions are needed to better assess the association between visceral adiposity with severity of AP.

\section{Conclusions}

The results of this study suggest that VAT and the VAT/ SMT ratio are strong predictors of severity, mortality, and systemic complications in AP patients.

\section{Abbreviations}

ANC: Acute necrotic collection; AP: Acute pancreatitis; APACHE-II: Acute Physiology and Chronic Health Evaluation II; APFC: Acute peripancreatic fluid collection; BISAP: Bedside Index of Severity in Acute Pancreatitis; BMI: Body mass index; CT: Computed tomography; ICU: Intensive care unit; MAP: Mild acute pancreatitis; MRI: Magnetic resonance imaging; ROC: Receiver operating characteristic; SAP: Severe acute pancreatitis; SIRS: Systemic inflammatory response syndrome; SMT: Skeletal muscle tissue; VAT: Visceral adipose tissue; WON: Walled-off necrosis

\section{Acknowledgments}

Not applicable.

\section{Authors' contributions}

Study conception and design: LX, JX. Acquisition of data: YP, J, LuX, YP. Statistical analysis: YL, YP, JX. Analysis and interpretation of data: All authors. Drafting of manuscript: JX, LuX, PL. Critical revision: All authors. Guarantor of article: LX. All authors approved the final version of the article, including the authorship list.

\section{Funding}

This study was supported by National Natural Science Foundation of China (No. 81300703 to L.X). Zhejiang Provincial Natural Science Foundation of China (No. LY19H030002 to L.X, No. LQ18H160015 to P.L), and Natural Science Foundation of Ningbo (No. 2015 A610178 to Y.P, No. 2018A610385 to P.L), and the Medical Health Science and Technology Project of Zhejiang Provincial Health Commission (No. 2019KY571 to P.L).

\section{Availability of data and materials}

The datasets generated in the current study are available from the corresponding author on reasonable request.

\section{Ethics approval and consent to participate}

The study was approved by the Ethics Committee at Ningbo First Hospital, China (No. 2018-R013). Written informed consent of each patient was waived as it was a retrospective study.

\section{Consent for publication}

Not applicable.

\section{Competing interests}

The authors declare that they have no competing interests.

\section{Author details}

${ }^{1}$ College of Medicine, Ningbo University, Fenghua Road, Jiangbei District, Ningbo, Zhejiang Province 818, NO, China. ${ }^{2}$ Department of Gastroenterology, Ningbo First Hospital, No.59 Liuting Street, Haishu District, Ningbo, Zhejiang Province, China. ${ }^{3}$ Department of Radiology, Ningbo First Hospital, No.59 Liuting Street, Haishu District, Ningbo, Zhejiang Province, China. ${ }^{4}$ Laboratory of Digestive Diseases, Ningbo First Hospital, No.59 Liuting Street, Haishu District, Ningbo, Zhejiang Province, China.

Received: 12 November 2018 Accepted: 6 June 2019

Published online: 13 June 2019

\section{References}

1. Swaroop VS, Chari ST, Clain JE. Severe acute pancreatitis. JAMA. 2004; 291(23):2865-8.

2. Whitcomb DC. Acute pancreatitis. N Engl J Med. 2006;354(20):2142-50.

3. Banks PA, Freeman ML. Practice guidelines in acute pancreatitis. Am J Gastroenterol. 2006;101(10):2379.

4. Larvin M, Mcmahon M. APACHE-II score for assessment and monitoring of acute pancreatitis. Lancet. 1989;334(8656):201-5.

5. Wu BU, Johannes RS, Sun X, Tabak Y, Conwell DL, Banks PA. The early prediction of mortality in acute pancreatitis: a large population-based study. Gut. 2008:57(12):1698-703.

6. Ranson JH, Pasternack BS. Statistical methods for quantifying the severity of clinical acute pancreatitis. J Surg Res. 1977;22(2):79-91.

7. Hilal MA, Armstrong T. The impact of obesity on the course and outcome of acute pancreatitis. Obes Surg. 2008;18(3):326-8.

8. Martinez J, Sanchez-Paya J, Palazon J, Suazo-Barahona J, Robles-Diaz G, Perez-Mateo M. Is obesity a risk factor in acute pancreatitis? A meta-analysis. Pancreatology. 2004;4(1):42-8.

9. Martinez J, Johnson C, Sanchez-Paya J, De Madaria E, Robles-Diaz G, PerezMateo M. Obesity is a definitive risk factor of severity and mortality in acute pancreatitis: an updated meta-analysis. Pancreatology. 2006;6(3):206-9.

10. Yoon SB, Choi MH, Lee IS, Lim C-H, Kim JS, Cho YK, Park JM, Lee B-I, Cho YS, Choi M-G. Impact of body fat and muscle distribution on severity of acute pancreatitis. Pancreatology. 2017;17(2):188-93.

11. Sadr-Azodi O, ., Orsini N, ., ? A-S, Wolk a, . Abdominal and total adiposity and the risk of acute pancreatitis: a population-based prospective cohort study. Am J Gastroenterol 2013, 108(1):133-139.

12. Sempere L, Martinez J, De Madaria E, Lozano B, Sanchez-Paya J, Jover R, Perez-Mateo M. Obesity and fat distribution imply a greater systemic inflammatory response and a worse prognosis in acute pancreatitis. Pancreatology. 2008:8(3):257-64.

13. Ji T, Li X, Zhang X, Hui L, Shang F, Zhu X, Guo L, Xu Y. Evaluation of the severity of hyperlipidemia pancreatitis using CT-measured visceral adipose tissue. J Clin Gastroenterol. 2018.

14. Yashima Y, Isayama H, Tsujino T, Nagano R, Yamamoto K, Mizuno S, Yagioka H, Kawakubo K, Sasaki T, Kogure H. A large volume of visceral adipose tissue leads to severe acute pancreatitis. J Gastroenterol. 2011:46(10):1213.

15. O'Leary D, O'Neill D, McLaughlin P, O'Neill S, Myers E, Maher M, Redmond H. Effects of abdominal fat distribution parameters on severity of acute pancreatitis. World J Surg. 2012;36(7):1679-85.

16. Natu A, Stevens T, Kang L, Yasinow S, Mansoor E, Lopez R, Glessing B, Remer E, Richards T, Gupta A. Visceral adiposity predicts severity of acute pancreatitis. Pancreas. 2017:46(6):776-81.

17. Petrov MS. Editorial: abdominal fat: a key player in metabolic acute pancreatitis. Am J Gastroenterol. 2013;108(1):140-2.

18. Banks PA, Bollen TL, Dervenis C, Gooszen HG, Johnson CD, Sarr MG, Tsiotos GG, Vege SS. Classification of acute pancreatitis-2012: revision of the Atlanta classification and definitions by international consensus. Gut. 2013; 62(1):102-11.

19. Thoemmes F. Propensity score matching in SPSS. In: arXiv preprint arXiv: 12016385; 2012

20. Marshall JC, Cook DJ, Christou NV, Bernard GR, Sprung CL, Sibbald WJ. Multiple organ dysfunction score: a reliable descriptor of a complex clinical outcome. Crit Care Med. 1995:23(10):1638-52

21. Irlbeck T, Massaro J, Bamberg F, O'donnell C, Hoffmann U, Fox C. Association between single-slice measurements of visceral and abdominal subcutaneous adipose tissue with volumetric measurements: the Framingham heart study. Int J Obes. 2010;34(4):781.

22. Aubrey J, Esfandiari N, Baracos V, Buteau F, Frenette J, Putman C, Mazurak V. Measurement of skeletal muscle radiation attenuation and basis of its biological variation. Acta Physiol. 2014;210(3):489-97.

23. Koda M, Senda M, Kamba M, Kimura K, Murawaki Y. Sonographic subcutaneous and visceral fat indices represent the distribution of body fat volume. Abdom Imaging. 2007;32(3):387-92. 
24. Gronemeyer SA, Steen RG, Kauffman WM, Reddick WE, Glass JO. Fast adipose tissue (FAT) assessment by MRI. Magn Reson Imaging. 2000;18(7): 815-8.

25. Maurovich-Horvat P, Massaro J, Fox C, Moselewski F, O'donnell C, Hoffmann $U$. Comparison of anthropometric, area-and volume-based assessment of abdominal subcutaneous and visceral adipose tissue volumes using multidetector computed tomography. Int J Obes. 2007;31(3):500.

26. Dobszai D, Mátrai P, Gyöngyi Z, Csupor D, Bajor J, Erőss B, Mikó A, Szakó L, Meczker Á, Hágendorn R. Body-mass index correlates with severity and mortality in acute pancreatitis: a meta-analysis. World J Gastroenterol. 2019; 25(6):729.

27. Ogden $\mathrm{CL}$, Carroll MD, Kit BK, Flegal KM. Prevalence of childhood and adult obesity in the United States, 2011-2012. JAMA. 2014;311(8):806-14.

28. Yang Y-X, Li L. Evaluating the ability of the bedside index for severity of acute pancreatitis score to predict severe acute pancreatitis: a meta-analysis. Med Princ Pract. 2016;25(2):137-42.

29. Staubli SM, Oertli D, Nebiker CA. Laboratory markers predicting severity of acute pancreatitis. Crit Rev Clin Lab Sci. 2015;52(6):273-83.

30. Di M-Y, Liu H, Yang Z-Y, Bonis PA, Tang J-L, Lau J. Prediction models of mortality in acute pancreatitis in adults: a systematic review. Ann Intern Med. 2016;165(7):482-90

31. Goyal H, Awad H, Hu Z-D. Prognostic value of admission red blood cell distribution width in acute pancreatitis: a systematic review. Annals of translational medicine. 2017;5(17).

32. Mounzer R, Langmead CJ, Wu BU, Evans AC, Bishehsari F, Muddana V, Singh VK, Slivka A, Whitcomb DC, Yadav D. Comparison of existing clinical scoring systems to predict persistent organ failure in patients with acute pancreatitis. Gastroenterology. 2012;142(7):1476-82.

33. Vege SS, DiMagno MJ, Forsmark CE, Martel M, Barkun AN. Initial medical treatment of acute pancreatitis: American Gastroenterological Association Institute technical review. Gastroenterology. 2018;154(4):1103-39.

34. Wang T, Ma X, Peng D, Zhang R, Sun X, Chen M, Yan J, Wang S, Yan D, He $Z$. Effects of obesity related genetic variations on visceral and subcutaneous fat distribution in a Chinese population. Sci Rep. 2016;6:20691.

35. Pulit SL, Karaderi T, Lindgren CM. Sexual dimorphisms in genetic loci linked to body fat distribution. Biosci Rep. 2017;37(1):BSR20160184.

36. Kanaley J, Sames C, Swisher L, Swick A, Ploutz-Snyder L, Steppan C, Sagendorf K, Feiglin D, Jaynes E, Meyer R. Abdominal fat distribution in pre-and postmenopausal women: the impact of physical activity, age, and menopausal status. Metabolism-Clinical and Experimental. 2001;50(8):976-82.

37. Yoneshiro T, Aita S, Matsushita M, Okamatsu-Ogura Y, Kameya T, Kawai Y, Miyagawa M, Tsujisaki M, Saito M. Age-related decrease in cold-activated brown adipose tissue and accumulation of body fat in healthy humans. Obesity. 2011;19(9):1755-60.

38. Gibbs J, Cull W, Henderson W, Daley J, Hur K, Khuri SF. Preoperative serum albumin level as a predictor of operative mortality and morbidity: results from the national VA surgical risk study. Arch Surg. 1999;134(1):36-42.

39. Blamey S, Imrie C, O'neill J, Gilmour W, Carter DC. Prognostic factors in acute pancreatitis. Gut. 1984;25(12):1340-6.

\section{Publisher's Note}

Springer Nature remains neutral with regard to jurisdictional claims in published maps and institutional affiliations.

Ready to submit your research? Choose BMC and benefit from:

- fast, convenient online submission

- thorough peer review by experienced researchers in your field

- rapid publication on acceptance

- support for research data, including large and complex data types

- gold Open Access which fosters wider collaboration and increased citations

- maximum visibility for your research: over $100 \mathrm{M}$ website views per year

At $\mathrm{BMC}$, research is always in progress.

Learn more biomedcentral.com/submissions 